\title{
Reflexões sobre a comensalidade nas ações de assistência alimentar em tempos de Covid-19: uma vivência no Movimento Fazendinhando
}

An exploration of comennsality in food assistance actions in Covid-19 times: the experience of Fazendinhando Movement

Reflexiones sobre comensalidad en acciones de ayuda alimentaria en tiempos de Covid-19: una experiencia del Movimiento Fazendinhando

Nathália César Nunes ${ }^{1}$, Kamilla Bianca Amaral e Silva², Fabiana Bom Kraemer ${ }^{3}$

\section{Introdução}

O Brasil tem vivenciado uma crise sanitária a partir do avanço da pandemia de COVID-19, que tem colocado em evidência as desigualdades sociais de um país com um pacto político formado em torno do neoliberalismo que tem se demonstrado incapaz de universalizar os direitos essenciais e fundamentais, mantendo-os privilégios de poucos.

São numerosas as notícias sobre a disseminação da COVID-19 no país e como ela vem alcançando o território nacional de maneira desigual, em consonância com as inúmeras assimetrias de diferentes origens como a geográfica, densidade demográfica e condições socioeconômicas.

Essa conjuntura somada à necessidade de isolamento físico gera recuos nos rendimentos da população, em especial dos grupos mais vulneráveis, e a consequente queda no consumo, e o esgotamento da capacidade familiar de endividamento. O avanço de insegurança alimentar nesse cenário é dado por restrições de renda, que dificultam o acesso aos alimentos ${ }^{(1)}$.

A pesquisa 'Pandemia na Favela', realizada pelo, Data Favela, entre os dias 20 e 22 de março do ano de 2020 com o objetivo de investigar o impacto da pandemia nas comunidades do Brasil, revelou que $86 \%$ dos moradores de favelas

\footnotetext{
${ }^{1}$ Departamento de Nutrição. Faculdade de Saúde Pública da Universidade de São Paulo. São Paulo, Brasil.E-mail: nattynunes@hotmail.com

2 Movimento Fazendinhando e moradora da comunidade Jardim Colombo, Complexo Paraisópolis, São Paulo, SP, Brasil. E-mail: kamillabaes@gmail.com

${ }^{3}$ Departamento de Nutrição Aplicada do Instituto de Nutrição da Universidade do Estado do Rio de Janeiro, Brasil. E-mail: fkraemer@uerj.br
} 
iriam passar fome durante a pandemia, caso não houvesse ações específicas voltadas para essa população. A pesquisa, divulgada pelo jornal 'Folha de São Paulo' (2), noticiava que "Em quarentena, $72 \%$ dos moradores de favelas tem padrão de vida rebaixado" e informava ainda que 13,6 milhões de pessoas moram nas favelas brasileiras, e que dessas uma em cada três teriam dificuldades na compra de itens básicos de sobrevivência, como alimentos durante o período de isolamento físico.

Mais de quatro meses dessa reportagem se passaram e, a resposta do poder público não chega com a presteza que o momento exige, como foi o caso da aprovação e liberação pelo governo federal do Auxílio Emergencial no valor de $R \$$ 600,00 para trabalhadores informais, microempreendedores individuais autônomos e desempregados, que para muitas famílias brasileiras tem sido a única forma de renda durante o isolamento. Vale destacar ainda que, segundo a pesquisa do Data Favela, citada anteriormente, $41 \%$ das famílias nas favelas brasileiras que solicitaram o auxílio emergencial não conseguiram receber nenhuma das parcelas do benefício até a data da realização da pesquisa ${ }^{(2)}$.

Em um país em que o Estado vem perdendo relevância como assegurador da segurança alimentar e nutricional (SAN) vê-se crescente a reconfiguração da sociedade civil para atender a demanda urgente de falta de alimentos com ações de mobilização para assistência alimentar. Segundo o, Data Favela (2), para oito em cada dez famílias moradoras das favelas brasileiras, as doações e o auxílio foi o que garantiu condições para se alimentarem, comprar produtos de higiene e limpeza ou pagar as contas mais básicas.

No entanto, a garantia a segurança alimentar e nutricional contempla além do acesso regular e permanente a alimentos de qualidade, em quantidade suficiente, o respeito à diversidade cultural (3). Assim, observamos que em tempos de pandemia outras dimensões da SAN podem estar comprometidas e reconfigurações nos modos de se alimentar são vivenciadas. A relação dos indivíduos com a comida pode ser, forçadamente ou não, modificada por diversas questões. O acesso aos alimentos, à responsabilidade do preparo de todas as refeições da família, a falta da alimentação escolar, a diminuição da renda familiar oriunda, em sua maioria, pelo aumento do desemprego, são algumas das questões que podem contribuir para as 
mudanças alimentares da população, o que pode se agravar, principalmente, nas periferias ${ }^{(4)}$. Essa afirmativa se dá pelo fato de que os territórios periféricos se caracterizam por dificuldades de acessos, alta densidade de construções, muitas pessoas dividindo a mesma moradia, habitações precárias e insuficiente oferta de serviços públicos essenciais, como abastecimento de água e coleta de lixo ${ }^{(5)}$. Assim, todos estes fatores podem contribuir para o agravamento do impacto da pandemia de COVID-19 na SAN nestes territórios ${ }^{(6)}$.

Porém, muitas das discussões realizadas nesses últimos meses nas mídias sociais sobre a alimentação durante a pandemia não particularizam a experiência dos sujeitos. Dessa maneira, vale salientar que alguns dos aspectos que permeiam as modificações dos modos de comer, nesse processo de pandemia, são muitas das vezes generalizados e, considerados como uma experiência global. Mas, essas reconfigurações, principalmente, nesse período de quarentena, não são vividas de forma homogênea, e nem afetam a todos da mesma maneira.

Portanto, imbuídas pelo questionamento de como se dão os modos de comer nas comunidades durante a pandemia, o objetivo deste estudo narrativo é refletir sobre os significados das ações para assistência alimentar do movimento social Fazendinhando da comunidade Jardim Colombo no contexto atual da pandemia de COVID-19 a partir do conceito de comensalidade.

Trata-se do "lugar de olhar" das pesquisadoras desse texto sobre uma vivência no projeto Fazendinhando. A escolha pela abordagem narrativa (7) permitiu explorar as experiências subjetivas de uma integrante do projeto social, videomaker, fotógrafa e moradora da comunidade Jardim Colombo. A narrativa, permitiu a interpretação que envolve a experiência do pesquisador e pesquisado no momento da entrevista, bem como as experiências anteriores de ambos. Entrecruzamos o relato narrativo de nossa interlocutora com recortes de conteúdo digital sobre as ações do projeto.

O acesso à experiência ocorreu por meio de uma palestra online, oferecida no mês de abril do ano de 2020 pela Faculdade de Saúde Pública da Universidade de São Paulo com o tema sobre a pandemia nas comunidades. Posteriormente, manteve-se interação contínua através de mensagens trocadas por um aplicativo multiplataforma de mensagens instantâneas e, por fim, foi conduzida uma entrevista 
semiestruturada por meio de um serviço de comunicação por vídeo. Cabe ainda salientar, que uma das autoras desenvolve projeto de doutoramento no Complexo Paraisópolis onde está situado o projeto Fazendinhando. Houve aprovação pelo Comitê de ética da Faculdade de Saúde Pública da Universidade de São Paulo sob o número: 29139719.0.0000.5421.

O movimento Fazendinhando nasceu em 2018 e surgiu a partir da ideia de transformar um local de descarte de entulho denominado Fazendinha, pois originalmente localizava-se uma fazenda, em um parque, dando também origem ao nome do movimento social. O projeto é composto por moradores e pessoas de fora da comunidade. Em março de 2020, com a disseminação da pandemia de COVID19, os integrantes do Fazendinhando perceberam a necessidade de realizar ações coletivas que ajudassem a comunidade Jardim Colombo nesse período uma vez que durante a pandemia, vários coletivos e organizações sociais atuantes nos bairros periféricos focam sua atenção em uma questão fundamental e tão preocupante quanto o próprio coronavírus: a comida, ou no caso, a falta dela em muitas panelas e armários segundo relato da integrante entrevistada.

\section{A comensalidade e o movimento Fazendinhando}

O lugar de partida para pensar as reconfigurações nos modos de comer de um grupo de moradores da comunidade Jardim Colombo, é o conceito de comensalidade tradicionalmente designado a partilha do mesmo alimento, do mesmo momento e, do mesmo local das refeições ${ }^{(8)}$. O comer, no entanto, é uma escolha inscrita na ordem da cultura e, construído na história de cada grupo social, revestido de aspectos simbólicos e sociais ${ }^{(9)}$.

Fichler e Masson (10) ao estudarem os modos de comer na França, Itália, Suíça, Alemanha, Inglaterra e Estados Unidos evidenciaram diferentes modelos alimentares entre esses povos, por exemplo, os americanos pesquisados tinham a alimentação como uma responsabilidade individual, onde cada um possuía a liberdade de escolher o que comer dentro da gama de opções oferecidas. Segundo o estudo, essa escolha era fortemente influenciada pelos conhecimentos sobre as propriedades nutricionais dos alimentos. Os franceses entrevistados valorizavam a 
sociabilidade alimentar, o que denominavam de convivialidade, ou seja, comer um prato dito tradicional, entre amigos e/ou familiares, com tempo e num lugar agradável aproximando-se da comensalidade descrita por Poulain (8) e incorporando os traços de hospitalidade, mostrando um vínculo entre comensalidade e convivialidade ${ }^{(11)}$.

Corroborando com essa noção de convivialidade, Fernandes (12), afirma que compartilhar a mesma refeição é uma maneira de aproximar os indivíduos, remetendo à lembranças diversas, como, por exemplo, de uma família que compartilha comida, espaço e tempo, os conduzindo a momentos de sociabilidade que, por vezes, permitem os comensais a superarem o sofrimento derivado dos condicionantes socioeconômicos que estes enfrentam em seus cotidianos.

O conceito de comensalidade revela que $\mathrm{o}$ ato de comer junto envolve muito mais do que simplesmente o que se come. Este compartilhamento de comida é um ato permeado por significados e simbolismos intrínsecos à complexidade do ato alimentar ${ }^{(11)}$. As práticas de comensalidade relacionam-se não apenas à ingestão de alimentos, mas também aos modos de comer, e exprimem hábitos culturais, atos simbólicos, regras de organização social e valores, além do compartilhamento de experiências ${ }^{(13)}$.

Segundo Woortmann (p.3) (14):

\begin{abstract}
O caráter simbólico-ritual do comer se expressa claramente no hábito de convidar pessoas para jantar em nossa casa, no "jantar fora" em determinadas ocasiões ou no "almoço de domingo". Nessas, e em outras ocasiões análogas, há mais em jogo que necessidades nutricionais. Não convidamos pessoas para jantar em nossa casa para alimentá-las, enquanto corpos biológicos, mas para alimentar e reproduzir relações sociais, isto é, para reproduzir o corpo social, o que supõe que sejamos em troca convidados a comer na casa do nosso convidado. O que está em jogo é o princípio da reciprocidade e da comensalidade. A presença da comida é, contudo, central, reconstruindo-se necessidades biológicas em necessidades sociais.
\end{abstract}

Segundo Lashley, Morrinson e Randall (15) é essa forma de olhar para a comensalidade imbuída de aspectos sociais e simbólicos que tornam o comer junto uma importante forma de fortalecer os laços entre as pessoas. Para Tuoumainen (16) significa, na maioria dos contextos culturais, uma expressão de unidade social. Ela implica no exercício de sociabilidade, que é descrita por Baechler (17) como a 
capacidade humana de estabelecer laços, conectando, mesmo que momentaneamente, os indivíduos envolvidos.

Observa-se, assim, que uma característica da comensalidade é a relação que o comensal estabelece com o outro no ato de comer. Seja um ambiente privado ou público, a comensalidade se faz presente sempre que comemos juntos, mas pode se manifestar também quando comemos separados ${ }^{(9)}$ e até mesmo quando a comida se encontra ausente como estudado por Leite e colaboradores (18) no documentário Garapa, que abordou o problema da fome no Brasil.

Nos dias atuais, os códigos de comensalidade não estão sujeitos às fronteiras culturais, sociais, regionais ou nacionais; os produtos disponíveis à mesa obedecem, cada vez mais, à lógica do capitalismo global dialogando ao mesmo tempo com os modos de comer na cultura local. Comensais de distintos grupos podem compartilhar gostos e produtos de uma mesma marca, por exemplo. Além disso, incorporam as transformações tecnológicas das indústrias da informação e comunicação podendo-se comer virtualmente, compartilhando fotos de comida (9). Nesse estudo, sem perder de vista a complexidade dos aspectos em torno da comensalidade, nos interessamos, em especial, aos aspectos da sociabilidade nas práticas alimentares, entendendo-a como processos interativos em que os indivíduos escolhem as formas de comunicação e as trocas que os ligam aos outros (19) ampliando os contextos de espaço.

A alimentação permeia grande parte das relações do cotidiano, sendo estas individuais ou coletivas, e compõem um núcleo de relações mais íntimas e mais compartilhadas. A sociabilidade manifesta-se na comida que se compartilha ${ }^{(11)}$.

Em períodos de pandemia, a importância de se discutir a comensalidade se dá pela possibilidade de refletir de forma crítica sobre a maneira como os modos de vida, condicionados por fatores econômicos, políticos e culturais, influenciam nos comportamentos alimentares das populações.

O avanço da COVID-19 no Brasil e a necessidade de interrupção das atividades cotidianas para frear o crescimento do vírus tem, no campo da Alimentação, suscitados diversos debates como mudanças nas práticas alimentares e as incertezas que perpassam o setor de alimentos seja em nível de produção, distribuição, comercialização ou preparo domiciliar. A condição de insegurança 
alimentar e nutricional instalada no país é agravada pelo SARS-Cov-2, sendo observada em inúmeras comunidades como Jardim Colombo, localizada no Complexo Paraisópolis, constituído por três núcleos - Paraisópolis, Jardim Colombo e Porto Seguro, situando-se parte na zona oeste e parte na zona sul da cidade de São Paulo.

A comunidade Jardim Colombo, a única do Complexo Paraisópolis, que se encontra na zona oeste, da cidade de São Paulo, têm aproximadamente, 17 mil habitantes e, se assemelha a uma cidade do interior por estar compreendida em um território pequeno, "o que reflete nos encontros na rua, no comércio local que faceia a calçada e nas crianças brincando e correndo pelas vielas" (20).

De acordo com dados de uma pesquisa realizada em 2015, a comunidade é formada, em grande parte, por moradores com baixo nível educacional; 8,1\% nunca estudaram, 36,4\% não concluíram o Ensino Fundamental e 10,6\% não concluíram o Ensino Médio. A maioria dos moradores recebia entre 01 e 02 salários-mínimos e mais de $30 \%$ dos entrevistados empregavam-se na economia informal. Trabalhos relacionados a tarefas domésticas como, limpeza e cuidado de idosos e crianças, foram bastante relatados nas entrevistas e, para garantir a sobrevivência, alguns ainda se dedicavam a reciclar resíduos de diferentes tipos. A comunidade, ainda, convive com diversos problemas de infraestrutura, como: depreciação da paisagem, ocupação irregular em terrenos particulares, desarticulação e fragmentação do tecido urbano, riscos ambientais em áreas ocupadas por lixo orgânico gerando a contaminação do solo, córrego poluído ocasionando enchentes no entorno em períodos de chuva e espaços livres degradados ${ }^{(20)}$.

Com o avançar da pandemia de Covid-19, observa-se muitos grupos, tanto de moradores das comunidades como de pessoas de fora dela, se organizando para levar comida para quem, nesse momento principalmente, não está tendo acesso ou está com dificuldades de tê-lo. Situação essa também vivenciada na comunidade Jardim Colombo. Segundo Andrade e Vaistman (21), o contexto brasileiro contraria a tese de que a dificuldade de sobrevivência, a educação deficiente e a baixa renda per capita são fatores que desfavorecem a mobilização da população em torno de interesses comuns. No Brasil, as organizações de mobilização e distribuição de 
recursos para pessoas em situação de carência se proliferaram, na década de 1990, sob a égide da solidariedade.

O Movimento Fazendinhando, surgido em 2018, vem se articulando e trabalhando para que a comunidade tenha, principalmente nesse período de pandemia, comida na mesa.

O movimento tem sua origem a partir de um projeto de transformação espacial de um terreno de 1000 metros quadrados da chamada antiga Fazendinha que se tornou um lixão. Em 2017, sob um olhar voltado para ressignificações, os idealizadores do projeto, uma arquiteta moradora da comunidade e seu pai, presidente da União dos Moradores, viram o referido lixão como um potencial espaço de lazer para a comunidade - o Parque Fazendinha. A revitalização do terreno foi inspirada no sucesso do Parque Sitiê - transformação que ficou mundialmente conhecida pela construção de um parque em uma zona de descarte no Morro do Vidigal na cidade do Rio de Janeiro.

O Movimento Fazendinhando que, antes da pandemia, era constituído por oito integrantes, nos meses iniciais da pandemia no Brasil incorporou mais de 20 voluntários entre moradores e pessoas de fora da comunidade.

Ao mesmo tempo que o local era revitalizado através de mutirões de limpeza para retirada do entulho e a construção de muralhas de pneus para alinhar o terreno, foram sendo realizadas diversas atividades culturais no local, com o objetivo, segundo relato da integrante do projeto entrevistada, de construir e fortalecer o sentimento de pertencimento dos moradores com aquele novo espaço de sociabilidade. Com a pandemia, além dessas ações de revitalização e integração do espaço, os integrantes do movimento realizaram a primeira campanha de financiamento coletivo o que possibilitou ajudar 27 famílias com a doação de comida, roupas e itens de higiene.

A voluntária entrevistada nos conta que algumas dessas famílias cadastradas no projeto, em um primeiro momento, receberam as doações entregues pessoalmente por eles, e assim, foi possível observar a gratidão dessas pessoas e a necessidade de continuarem com a campanha de arrecadações. Posteriormente, com o aumento no número de arrecadações, as doações passaram a ser entregues 
em dia e horário agendado pelos integrantes e voluntários do projeto para que não houvesse aglomeração durante a entrega.

Em cinco meses foi possível doar 650 cestas básicas e mais 650 cestas de legumes, por semana, com a ajuda de parceiros e empresas externas à comunidade, beneficiando, aproximadamente, 05 mil famílias no total.

Ações como essas colocam em evidência a capacidade de organização da sociedade civil e uma oportunidade para a troca de conhecimento e cooperação entre seus participantes observada no compartilhamento de alimentos e refeições prontas, ou seja, em uma forma de comensalidade vivenciada na comunidade através de ações sociais.

As sociabilidades alimentares como processos interativos geram-se em contextos delimitados no espaço e no tempo, em casa e fora de casa, desenrolandose durante momentos que os alimentos estão presentes (19). Oliveira e Prado (22), deslocam a mesa física, para a mesa metafísica, ou seja, a mesa e, principalmente, a comida vista como meios para além das suas expressões físicas, mas sim expressões de significados, que residem assim no campo do abstrato. Oliveira, Barcellos e Prado (p.142) (23) falam que:

Entendemos que a relação entre comensais não se dá somente no nível da congregação à mesa, mas também pode-se comer junto e o espaço dessa comida ser desagregador. Pode-se comer junto, estando-se separado. Pode-se comer separado, estando-se junto. Pode-se ainda comer sozinho, estando-se sozinho ou não. Ou seja, o ato de comer como ato deflagrador das vibrações da comensalidade não se restringe a com quem se come; mas, de forma mais abrangente, onde se come, como se come, por que se come, quando se come e qual o estado de alma que se expressa no ato de comer.

A proposta dos autores faz-nos pensar na comensalidade se ampliando no espaço e em situações que podem ser diferenciadores de sociabilidades como nas ações de doações de alimentos. A complexidade vista no ato de comer transborda na partilha dos alimentos transformando a relação que temos com quem está ao nosso redor mesmo que não se coma junto. A nossa entrevistada nos relatou que "o senso de coletividade que sempre se fez presente, obtém maior força durante este período que estamos vivendo, onde formas de construções sociais são repensadas e recriadas." Ainda segundo ela, durante esses últimos meses com a realização das 
arrecadações e doações foi possível conhecer muitos vizinhos e moradores da própria comunidade que até então não se conhecia.

Assim destacamos, o significado da comida como elemento que reúne pessoas e ganha formas de colaboração mais firmes e densas durante a pandemia de COVID-19, fortalecendo o espaço da comunidade como uma unidade social. Podemos atribuir, em momentos de falta de alimentos, um significado a comida atribuída à necessidade básica, item de sobrevivência, mais do que em momentos de acesso. No entanto, observamos que além de primeira necessidade, é o elemento que une. A sociabilidade imbuída na partilha do alimento mostra que na comunidade Jardim Colombo, para muitos não basta saciar sua própria fome, mas sim compartilhar a comida, saciando a fome e levando uma melhor qualidade de vida para quem está ao seu redor como ilustra a fala da nossa interlocutora "quem vive em favela sabe que a solidariedade é muito forte, principalmente, por causa das necessidades deste território". Ainda segundo ela, a ajuda acontece geralmente entre os próprios moradores com o objetivo de que ninguém passe fome. Ela fala que quem ganha uma cesta básica divide com o vizinho se este não tiver nada para comer.

Poulain (24) fala que "é pela cozinha e pelas maneiras à mesa que se produzem as aprendizagens sociais mais fundamentais e que uma sociedade transmite e permite a interiorização de seus valores".

Se por um lado vivenciamos uma escassez de proteção social do Estado, por outro observamos em movimentos como o Fazendinhando, um grande esforço coletivo para que todos tenham o que comer

Por meio da doação de alimentos é possível agir em conexão com o outro e constituir um meio de aprender sobre o outro e inserir-se - bem como manter-se simbolicamente vinculado a um determinado grupo. Durante o período da pandemia temos observado pessoas imbuídas em alimentar o outro mesmo quando falta comida para suas famílias. Essa sociabilidade identificada nas ações de doação de alimentos pode reforçar a identidade de muitos grupos sociais.

Com a pandemia, a estrutura da vida cotidiana de quem mora nas comunidades é colocada em evidência dando visibilidade ao que para muitos era invisível à sua realidade. A fome, nessa comunidade, não é um fenômeno oriundo 
da pandemia de COVID-19, mas decorrente dela é posta em evidência e agravada pelo aumento do desemprego. Enquanto nas mídias sociais se fala muito da espera ao retorno da normalidade ou da busca por um novo normal, nas comunidades escutamos que "não há novo normal para quem nunca teve nem o normal".

\section{Considerações finais}

Em meio a esse cenário de enfraquecimento do papel do Estado, movimentos sociais dentre outros têm reforçado a dimensão da solidariedade em defesa da vida, com base em ações que atendam às necessidades materiais, dentre elas de alimentos.

Através do conceito de comensalidade, sem pretensão de esgotar o tema, buscamos olhar essas ações de solidariedade e a ajuda mútua como elementos da sociabilidade alimentar que transbordam a mesa e que estabelecem relações sociais. Faz-se necessário aprofundar essa discussão com outras pesquisas capazes de observar, conhecer e tratar de compreender a natureza e a estrutura que articulam essa realidade social.

\section{Referências}

(1) Silva OJ, Gomes NN. O amanhã vai à mesa: abastecimento alimentar e COVID19. Cad. Saúde Pública 2020; 36(5):e00095220 [Acesso em 21 ago 2020]. Disponível em: https://doi.org/10.1590/0102-311X00095220.

(2) Folha de São Paulo. Em quarentena, $72 \%$ dos moradores das favelas tem estilo de vida rebaixado. [Acesso em 10 ago 2020] Disponível em: https://www1.folha.uol.com.br/equilibrioesaude/2020/03/em-quarentena-72-dosmoradores-de-favelas-tem-padrao-de-vida-rebaixado.shtml

(3) Conselho Nacional de Segurança Alimentar e Nutricional (CONSEA). Lei de Segurança Alimentar e Nutricional (LOSAN). Lei № 11.346, de 15 de setembro de 2006. [Acesso em 21 ago 2020]. Disponível em: http://www4.planalto.gov.br/consea/conferencia/documentos/lei-de-segurancaalimentar-e-nutricional

(4) Oliveira TC, Abranches MV, Lana RM. (In) Segurança alimentar no contexto da pandemia por SARS-CoV-2 Cad. Saúde Pública 2020; 36(4):e00055220.

(5) Instituto Brasileiro de Geografia e Estatística (IBGE). Aglomerados subnormais. O que é? [Acesso em 21 ago 2020). Disponível em: 
https://www.ibge.gov.br/geociencias/organizacao-do-territorio/tipologiasdoterritorio/15788-aglomerados-subnormais.html?=\&t=0-que-e

(6) Périssé at al. Nota técnica: Covid-19 e vulnerabilidades: considerações sobre proteção social nas favelas. Comitê Fiocruz Covid-19 nas Favelas. [Acesso em 21 ago 2020]. Disponível em: https://portal.fiocruz.br/documento/nota-tecnica-covid-19e-vulnerabilidades-consideracoes-sobre-protecao-social-nas-favelas

(7) Creswell JW. Investigação qualitativa e projeto de pesquisa: escolhendo entre cinco abordagens. Porto Alegre: Penso, 2014.

(8) Poulain JP. Sociologias da Alimentação. Tradução de Proença RPC, Rial CS, Conte J. Florianópolis: Ed. UFSC, 2004.

(9) Wollz LEB, Prado SD. Cinema e comensalidade: aspectos simbólicos da comida a partir da linguagem cinematográfica. In: Ferreira FR, Prado SD, Seixas C.M, Vargas EP. (Org.). Cinema e comensalidade. Série Sabor Metrópole. 2016; 6(1):3550.

(10) Fischler C, Masson E. Comer: a alimentação de franceses, outros europeus e americanos. Tradução de Ana Luíza Ramazzina Guirardi. São Paulo: Editora Senac, 2010.

(11) Boutaud J. Compartilhar a mesa. In: Montandon A. (Org.). O livro da hospitalidade. São Paulo: SENAC, 2011.

(12) Fernandes AT. Ritualização da comensalidade. Sociologia: Rev Facul Letras do Porto. 1997; 7(8):7-30.

(13) Fischler C. Commensality, society and culture. Social Science Information. 2011; 50:528-48.

(14) Woortmann K. A comida, a família e a construção de gênero. Brasília: UNB, 1985.

(15) Lashley C, Morrison A, Randall S. Uma refeição inesquecível! A hospitalidade como experiência emocional. In: Sloan D. (Org.). Gastronomia, restaurantes e comportamento do consumidor. São Paulo: Manole, 2005.

(16) Tuomainen $\mathrm{H}$. Eating alone or together? Commensality among Ghanaians in London. Anthropology of food, 2014; 10.

(17) Baechler J. Grupos e sociabilidade. In: Boudon, Raymond. (Org.). Tratado de sociologia. Rio de Janeiro: Jorge Zahar, 1995.

(18) Leite BFS, Coutinho CO, Costa JCG, Kraemer FB. Os sentidos da fome no filme Garapa. In: Ferreira FR, Prado SD, Seixas CM, Vargas EP. (Org.). Cinema e comensalidade. Série Sabor Metrópole. 2016; 6(1):209-236.

(19) Mascarenhas, MP. Sociabilidades em volta da mesa. In: Atas do VII Congresso Português de Sociologia. Lisboa: APS. 2012.

(20) Carro E, Leite MADFA. Refazendo a memória comunitária: o Parque Fazendinha do Jardim Colombo. V!RUS, 2018; 17.

(21) Andrade GB, Vaitsman J. Apoio social e redes: Conectando solidariedade e saúde. Ciência da Saúde Coletiva. 7(4):925-934. 
(22) Oliveira RG, Prado SD. A comensalidade no filme pai e filha, de yasujirô ozu: a aparente simplicidade do comer. Estudos socioculturais em alimentação e saúde: saberes em rede, 2016.

(23) Oliveira RG, Barcellos DMN, Prado SD.Corpo, consumos e comensalidade na cidade: reflexões sobre os afetos na publicidade. INTERIN. 2019; 24(1):139-156.

(24) Poulain JP. Sociologias da alimentação: os comedores e o espaço social alimentar. Tradução da Proença, RPC, Rial, CS. Florianópolis: UFSC, 2013. 